\title{
Impact of small promoter amounts on coke structure in dry reforming over $\mathrm{Ni} / \mathrm{ZrO}_{2}$
}

Received 00th January 20xx, Accepted 00th January 20xx
Robert Franz, ${ }^{\mathrm{a}, \mathrm{b}}$ Tobias Kühlewind, ${ }^{\mathrm{b}}$ Genrikh Shterk, ${ }^{\mathrm{c}}$ Edy Abou-Hamad, ${ }^{\mathrm{d}}$ Alexander Parastaev, Evgeny Uslamin, ${ }^{a}$ Emiel J.M. Hensen, ${ }^{\mathrm{e}}$ Freek Kapteijn, ${ }^{\mathrm{b}}$ Jorge Gascon, ${ }^{\mathrm{c}}$ Evgeny A. Pidko*a

\begin{abstract}
Coke deposition is one of the main challenges in the commercialization of dry reforming of methane over supported $\mathrm{Ni}$ catalysts. Besides the coke quantity, the structure of the deposits is also essential for the catalyst lifetime. Accordingly, in this study, we analysed the effect of different metal promoters on both these variables over $\mathrm{Ni} / \mathrm{ZrO}_{2}$ catalysts. Alkali metals are known to block the most active coke forming sites already at low loading, leading to an investigation of $\mathrm{Na}$, $\mathrm{K}$ and $\mathrm{Cs}$. To analyse the possible contributions of coke gasification activity of the alkali metals, Mn was additionally used as a comparison. While the conversion is barely affected by the type of promoter, it has profound effect on the amount and the composition of carbon deposits formed during reaction: Addition of $\mathrm{K}$ or $\mathrm{Mn}$ reduces the coke content to a similar degree but with less carbon fibres observed in the case of K. Promotion by Cs and Na results in the lowest coke content, which is attributed to enhanced coke gasification via carbonate species
\end{abstract}

\section{Introduction}

Current prognoses for worldwide energy consumption predict an increase in global $\mathrm{CO}_{2}$ emissions for all except the most optimistic scenarios. At the same time, the demand for various chemical products, especially plastics, will keep increasing and thereby also the consumption of fossil fuels. ${ }^{1}$ Recycling $\mathrm{CO}_{2}$ as a raw material for the chemical industry would lead to a reduction of $\mathrm{CO}_{2}$ emissions and at the same time help to meet growing customer demands. The so-called dry reforming of methane (1), in which carbon dioxide and methane react to synthesis gas at elevated temperatures, is a potential route to achieve this.

$$
\begin{gathered}
\mathrm{CH}_{4}+\mathrm{CO}_{2} \longrightarrow 2 \mathrm{CO}+2 \mathrm{H}_{2} \\
\Delta \mathrm{H}_{298 \mathrm{~K}}=247 \mathrm{~kJ} \mathrm{~mol}^{-1}
\end{gathered}
$$

The extensive experience of the (petro)chemical industry with the related process of methane steam reforming is a considerable advantage of dry reforming. However, one of the significant drawbacks of this process over steam reforming is the more extensive carbon formation, causing rapid

a. Inorganic Systems Engineering, Department of Chemical Engineering, Delft University of Technology, Van der Maasweg 9, 2629 HZ Delft, The Netherlands Email:e.a.pidko@tudelft.nl

b. Catalysis Engineering, Department of Chemical Engineering, Delft University of Technology, Van der Maasweg 9, 2629 HZ Delft, The Netherlands

c. Advanced Catalytic Materials, KAUST Catalysis Center, King Abdullah University of Science and Technology, Thuwal 23955, Saudi Arabia

d. Core Labs, King Abdullah University of Science and Technology, Thuwal 23955, Saudi Arabia

e. Laboratory of Inorganic Materials and Catalysis, Department of Chemical Engineering and Chemistry, Eindhoven University of Technology, P.O. Box 513, 5600 $M B$, Eindhoven, the Netherlands

Electronic Supplementary Information (ESI) available: [details of any supplementary information available should be included here]. See DOI: 10.1039/x0xx00000x deactivation of the catalyst during operation. ${ }^{2}$ The main coking reactions are the Boudouard reaction (2) and methane decomposition (3):

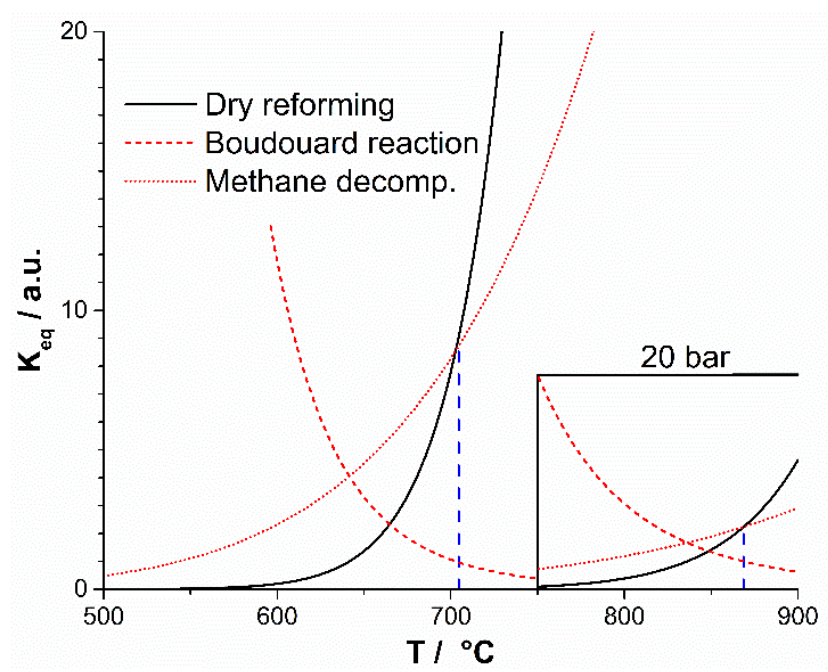

Fig. 1 Equilibrium constants of the dry reforming and the two main coking reactions as a function of temperature at 1 bar and 20 bar (insert); calculated using ASPEN V8.8, amended from ${ }^{15}$.

$$
\begin{gathered}
2 \mathrm{CO} \rightarrow \mathrm{CO}_{2}+\mathrm{C} \quad \Delta H_{298 K}=-171 \mathrm{~kJ} \mathrm{~mol}^{-1} \\
\mathrm{CH}_{4} \rightarrow 2 \mathrm{H}_{2}+\mathrm{C} \quad \Delta H_{298 K}=75 \mathrm{~kJ} \mathrm{~mol}^{-1}
\end{gathered}
$$

The comparison of thermodynamic equilibrium constants for the target dry reforming and the undesirable side-reactions shown in Fig. 1 highlights the fundamental challenges of this process, especially when aiming for large-scale industrial application. Ideally, the reaction temperature should be low to reduce energy consumption and thus costs. High-pressure 
operation would also be economically preferable to a compression of the more voluminous syngas for use in syntheses at elevated pressure (e.g., Fischer-Tropsch (FT) ${ }^{3}$ or methanol ${ }^{4}$ syntheses). ${ }^{5}$ At low temperature and high pressure, the side-reactions producing coke are thermodynamically most favourable, however (Fig. 1). According to thermodynamics, high temperature and low pressure operation is desired, if coke formation is to be minimized. A compromise of high temperature and pressure would lead to additional issues. Under such conditions, gas-phase reactions start becoming relevant, which also lead to coke formation. ${ }^{6}$ Coke formation appears, therefore, inevitable under practical conditions, which implies that a successful dry reforming catalyst should be highly resistant to coking. ${ }^{7}$

To develop a coke-resistant catalyst, both support and active phase need to be optimized. Precious metals such as $\mathrm{Ru}$ exhibit good performance but are scarce and expensive, shifting the research focus to alternative catalyst formulations based on earth-abundant $3 d$ transition metals. ${ }^{8}$ Amongst these, nickel is the most studied element due to its wide availability and high catalytic activity in dry reforming. ${ }^{9-11}$ The downside of nickel is its considerable susceptibility to coking. Depending on the reaction temperature, $\mathrm{Ni}$ catalysts can promote the formation of various types of coke, such as surface graphite, graphene as well as carbon fibers. ${ }^{12-14}$ The latter represent the most critical challenge as the growth of carbon fibres in the course of the catalytic process breaks catalyst particles and results in reactor plugging. ${ }^{8}$

One of the most popular strategies to improve the coke resistance of $\mathrm{Ni}$-based dry reforming catalysts is to deactivate the highly reactive sites on the surface by promoter addition. ${ }^{16-}$ 20 A representative example is the Sulphur PAssivated Reforming (SPARG) process developed by Haldor Tops $\varnothing \mathrm{e}^{21}$, in which the feed contains a controlled amount of $\mathrm{H}_{2} \mathrm{~S}$ poison. The $\mathrm{H}_{2} \mathrm{~S}$ chemisorbs on the $\mathrm{Ni}$ catalyst, deactivating the most active sites, which are also responsible for most of the coke formation. As a result, the catalyst operates with reduced activity but in a much more stable fashion over extended periods of time. ${ }^{22}$

Single-crystal studies of methane decomposition on $\mathrm{Ni}$ have shown that a similar effect is achieved with Au and K. ${ }^{23,}{ }^{24}$ Step sites on $\mathrm{Ni}$ clusters are the most active sites for coke formation and all above-mentioned promoters preferentially occupy these sites. ${ }^{25}$ Site blocking with alkaline and earth-alkaline oxides has already been investigated. ${ }^{18-20,26,27}$. Other additives such as $\mathrm{Mn}$ or $\mathrm{Sn}$ are also reported to reduce coking by blocking the $\mathrm{Ni}$ surface. ${ }^{28,} 29$ For the earth-alkaline metals and manganese a caveat must be added. Besides blocking the $\mathrm{Ni}$ surface, these promoters are also assumed to increase the $\mathrm{CO}_{2}$ affinity of the catalyst, additionally reducing the coking. Although the sitesensitivity of the Boudouard reaction has been studied less extensively, the literature points to similar trends as for methane decomposition for this process with a higher reactivity of the step-edge sites. ${ }^{30}$ Furthermore, it has been proposed that promoter ions may also affect the electronic structure of the neighbouring $\mathrm{Ni}$ centres, reducing their activity towards dissociative methane chemisorption. ${ }^{23}$ At the same time, alkal addition can enhance $\mathrm{Ni}$ sintering in select cases, meaning that a fine balance must be struck during synthesis. ${ }^{31-34}$

However, a detailed quantitative analysis of the effect on the coke structure of several different promoters operating through a similar mechanism has not been reported until now. Even small decreases in coking activity can delay exchange of the catalyst bed or result in a milder regeneration procedure, extending the catalyst lifetime further. Consequently, the alkali elements $\mathrm{Na}, \mathrm{K}$ and $\mathrm{Cs}$ were selected as the first batch of promoters. Potassium has been one of the prime examples of this site-blocking behaviour. Other alkali metals should thus represent a rather moderate change of promoter characteristics, allowing to probe the electronic effects mentioned previously. ${ }^{23}$ Amongst metal oxides, $\mathrm{MnO}_{x}$ has been reported as a promoter in dry reforming literature. ${ }^{29,}{ }^{35}$ As mentioned above, at high loadings of manganese, an increased $\mathrm{CO}_{2}$-affinity of the catalyst is noticeable. For low loadings, the physical blocking of $\mathrm{Ni}$ sites is expected to dominate. This apparent similarity in function made $\mathrm{MnO}_{x}$ an interesting comparison. In contrast to $\mathrm{MnO}_{x}$, alkali metals are well-known for their activity in gasification of carbon. ${ }^{36,37}$ Thus, manganese as the fourth promoter should also clarify, if this reaction contributes to the reduced coke content. All samples were supported on $\mathrm{ZrO}_{2}$ since it is less prone to forming mixed phases with $\mathrm{Ni}$ or the promoters, as is the case for $\mathrm{Al}_{2} \mathrm{O}_{3}$ or $\mathrm{SiO}_{2}$ (e.g. ${ }^{31}$, ${ }^{38}$ ). In contrast to other supports $\mathrm{ZrO}_{2}$-based catalysts also tend to form more coke, which is desirable in the analysis of the impact of the promoters on the coke structure. ${ }^{39}$

\section{Experimental}

\section{Chemicals}

Ethylenediaminetetraacetic acid (EDTA, ThermoFisher $99 \%$ ), $\mathrm{NH}_{3}$ solution (VWR, $25 \%$ ), $\mathrm{ZrO}_{2}$ (Alfa Aesar, $51 \mathrm{~m}^{2} / \mathrm{g}$ ), $\mathrm{Ni}\left(\mathrm{NO}_{3}\right)_{2} \cdot 6 \mathrm{H}_{2} \mathrm{O}$ (Merck, analysis quality), $\mathrm{KNO}_{3}$ (Acros, $99 \%+$ ), $\mathrm{NaNO}_{3}$ (Riedel-De Haen, $99.5 \%$ ), $\mathrm{CsNO}_{3}$ (AlfaAesar 99.5\%), $\mathrm{Mn}\left(\mathrm{NO}_{3}\right)_{2} \cdot 4 \mathrm{H}_{2} \mathrm{O}$ (ThermoFisher, analysis quality).

All materials were used without further modification except for $\mathrm{NH}_{3}$ (aq), which was diluted with demin. water in a volumetric ratio of $1: 1$ before usage, and $\mathrm{ZrO}_{2} . \mathrm{ZrO}_{2}$ extrudates were ground to a fine powder before impregnation.

\section{Catalyst synthesis}

All catalysts were synthesized via incipient wetness impregnation on commercial $\mathrm{ZrO}_{2}$ support. A solution of the required concentration was prepared in the following fashion: In a first step EDTA was dissolved in a solution of $12.5 \% \mathrm{NH}_{3}$. Afterwards, the required amount of $\mathrm{Ni}\left(\mathrm{NO}_{3}\right)_{2}$ and either $\mathrm{KNO}_{3}$, $\mathrm{NaNO}_{3}, \mathrm{CsNO}_{3}$ or $\mathrm{Mn}\left(\mathrm{NO}_{3}\right)_{2}$ were added to the solution. After the dissolution of all components, the required amount of liquid $\left(0.4 \mathrm{~mL} \mathrm{~g}^{-1}\right)$ was impregnated onto the dry $\mathrm{ZrO}_{2}$ powder. This was followed by thorough mixing, drying for $5 \mathrm{~h}$ at $80{ }^{\circ} \mathrm{C}$ and then calcination at $700{ }^{\circ} \mathrm{C}$ for $5 \mathrm{~h}$ (heating rate of $10 \mathrm{~K} \mathrm{~min}^{-1}$ ). For all samples the loading of $\mathrm{Ni}$ was set at $0.02 \mathrm{~g}_{\mathrm{Ni}} \mathrm{g}_{\text {support }}{ }^{-1}$. The amount of the promoter was calculated to achieve molar ratios promoter: $\mathrm{Ni}=1: 10$ or $1: 5$. In all syntheses a ratio of EDTA: $\mathrm{Ni}=$ 
1 maintained. An overview of the different catalysts in given in Table 1.

Table 1. Overview of the tested catalysts

\begin{tabular}{c|c|c}
\hline Promoter metal & Ratio promoter/ Ni & Abbreviation \\
\hline-- & -- & REF \\
$K$ & $1 / 10$ & $1 \mathrm{~K}$ \\
$\mathrm{~K}$ & $2 / 10$ & $2 \mathrm{~K}$ \\
$\mathrm{Cs}$ & $1 / 10$ & $1 \mathrm{Cs}$ \\
$\mathrm{Cs}$ & $2 / 10$ & $2 \mathrm{Cs}$ \\
$\mathrm{Na}$ & $1 / 10$ & $1 \mathrm{Na}$ \\
$\mathrm{Mn}$ & $1 / 10$ & $1 \mathrm{Mn}$
\end{tabular}

\section{Temperature programmed reduction (TPR)}

Temperature programmed reduction was carried out in a fixedbed reactor system. $100 \mathrm{mg}$ of freshly prepared sample was pelletized, crushed and sieved to a particle size of $212-355 \mu \mathrm{m}$ and filled into a quartz reactor (I.D. $6 \mathrm{~mm}$ ). The quartz reactor was placed into a furnace and a flow of $10 \% \mathrm{H}_{2} / \mathrm{Ar}(30 \mathrm{~mL}$ $\mathrm{min}^{-1}$ ) started. The furnace was then heated from room temperature to $900{ }^{\circ} \mathrm{C}$ with a rate of $5 \mathrm{~K} \mathrm{~min}^{-1}$. At the outlet, the hydrogen signal was monitored with a thermal conductivity detector (TCD). Peak deconvolution of the TPR data was carried by the superposition of three Gaussian functions for each profile.

\section{$\mathrm{H}_{2}$-Chemisorption}

Chemisorption was measured on a Micromeritics ASAP 2020C. Approx. $130 \mathrm{mg}$ of sample were loaded into the setup and reduced at $650{ }^{\circ} \mathrm{C}$ for $2 \mathrm{~h}$ in $20 \% \mathrm{H}_{2}$ in $\mathrm{N}_{2}$, thus mimicking the reduction conditions of the reactivity tests. Afterwards the sample was cooled down to $30^{\circ} \mathrm{C}$, at which $\mathrm{H}_{2}$ chemisorption was measured with a static-volumetric method.

\section{Electron microscopy}

ADF-STEM analysis and EELS elemental mapping of the samples were carried out with an FEl Titan $G^{2}$ 80-300 kV electron microscope operated at $300 \mathrm{kV}$. For the TEM analysis of the coked samples, a Jeol JEM 1400 plus TEM was used.

\section{Raman spectroscopy}

Raman spectra were obtained with a Renishaw Via Reflex confocal spectrometer using a $532 \mathrm{~nm}$ laser excitation. The laser power was set to $100 \%$ and the sample was irradiated for $10 \mathrm{~s}$ with 6 accumulations. The laser has a maximum power of $30 \mathrm{~mW}$.

\section{${ }^{13}$ C-MAS solid state NMR}

For the $1 \mathrm{D}{ }^{13} \mathrm{C}$ MAS NMR a known amount of sample was filled into zirconia rotors and recorded on a Bruker AVANCE III spectrometer. The system operated at resonance frequencies of $600 \mathrm{MHz}\left({ }^{1} \mathrm{H}\right.$ frequency), and a conventional double resonance $3.2 \mathrm{~mm}$ CPMAS probe was used. The spinning frequency was set to $10-15 \mathrm{kHz}$. NMR chemical shifts are reported with respect to TMS as the external reference. Spectra were recorded by a spin echo pulse sequence (pulse length $3.4 \mu \mathrm{s})$ with four-phase alternation synchronized with the spinning rate for the MAS experiments to delete all background signals from the probe. The interscan delay was set to $15 \mathrm{~s}$ to allow the complete relaxation, and 5,000-30,000 scans were performed. An apodization function (exponential) corresponding to a line broadening of $80 \mathrm{~Hz}$ was applied prior to the Fourier transformation.

\section{Reactivity tests}

The system used for catalytic testing has been described in detail in previous publications..$^{40}$ In short, it consists of a parallel fixed-bed reactor system with six reactors (quartz tubes with 4 $\mathrm{mm}$ I.D.). The quartz tubes are inserted into steel tubes mounted within the furnace to provide for better heat conduction. For each experiment the reactors were filled in the following manner (top to bottom): quartz wool plug, a $15 \mathrm{~cm} \mathrm{SiC}$ bed $(212-425 \mu \mathrm{m})$, a thin quartz layer, the catalytic bed, a thin quartz wool layer, a $10 \mathrm{~cm} \mathrm{SiC} \mathrm{bed,} \mathrm{a} \mathrm{quartz} \mathrm{wool} \mathrm{plug.} \mathrm{For} \mathrm{the}$ standard catalytic experiments, the catalyst bed consisted of 30 $\mathrm{mg}$ of catalyst $(212-355 \mu \mathrm{m})$ mixed with $70 \mathrm{mg}$ of $\mathrm{SiC}$ $(300-355 \mu \mathrm{m})$. These two components were mixed as described in literature to ensure proper distribution of the sample. ${ }^{41}$ For a detailed coke content analysis, catalytic runs were carried out with a catalytic bed of $75 \mathrm{mg}$ of undiluted catalyst $(212-355 \mu \mathrm{m})$, to allow for a full recovery of coked catalyst without $\mathrm{SiC}$ contamination. In all experiments the correct placement of the catalytic bed within the isothermal zone of the reactor was ensured.

The catalytic setup allowed for premixing the reaction mixture in a separate mixing section upstream of the reactors. The custom mixture was then fed to each reactor individually through separate mass flow controllers (MFCs). Activity testing was carried out as follows. To reduce the catalysts, the reactors were heated under a flow of $40 \mathrm{~mL} \mathrm{~min}^{-1}\left(20 \% \mathrm{H}_{2}\right.$ in $\left.\mathrm{N}_{2}\right)$ to 650 ${ }^{\circ} \mathrm{C}$ with a rate of $10 \mathrm{~K} \mathrm{~min}^{-1}$, followed by an isothermal period of $2 \mathrm{~h}$. Next, the feed was switched to the reaction mixture. For the catalytic activity tests, the feed consisted of $20 \% \mathrm{CO}_{2}, 20 \%$ $\mathrm{CH}_{4}$ and $60 \% \mathrm{~N}_{2}$. For the separate coking runs $50 \% \mathrm{CO}_{2}$ and $50 \% \mathrm{CH}_{4}$ were used. In both cases, the flow of gas per reactor was $80 \mathrm{~mL} \mathrm{~min}^{-1}$, keeping the reactant to catalyst ratio identical between the two sets of experiments $\left(32 \mathrm{~L}_{\mathrm{CH} 4} \mathrm{~g}^{-1} \mathrm{~h}^{-1}\right)$. All runs were carried out for a total of 12 hours. The coke content was determined with the aid of a TGA-MS (Mettler Toledo TGA/DSC1 connected to a Pfeiffer Vacuum OmniSTAR) by quantifying the $\mathrm{CO}_{2}$ signal while heating the sample using synthetic air as an oxidant.

Product analysis was carried out by a GC equipped with both an FID and a TCD. The TCD was used for the analysis of all gases (columns: $0.3 \mathrm{~m}$ Hayesep Q 80-100 mesh with back-flush, $25 \mathrm{~m}$ $\times 0.53 \mathrm{~mm}$ Porabond $\mathrm{Q}$, and $15 \mathrm{~m} \times 0.53 \mathrm{~mm}$ molsieve $5 \mathrm{~A}$ with bypass option) with $\mathrm{N}_{2}$ as the internal standard. The FID signal provided a quality check for the TCD signal. 


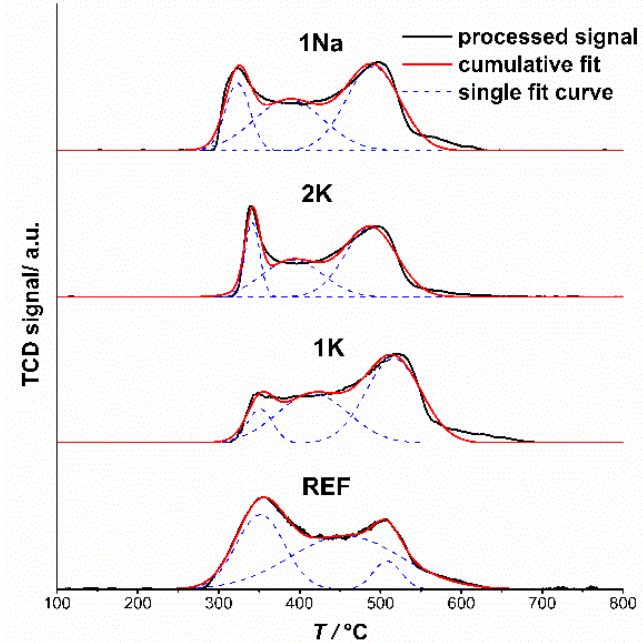

(a)

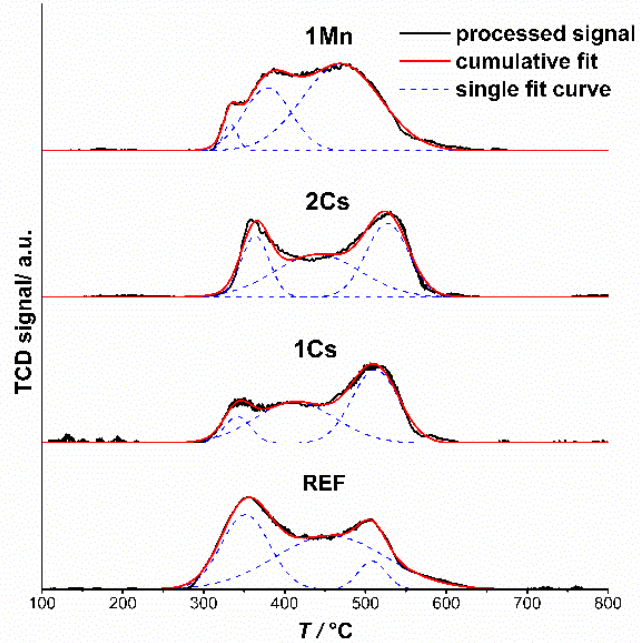

(b)

Fig. 2 TPR curves with peak deconvolution for K-promoted and Na-promoted (a, left) and Cs-promoted and Mn-promoted (b, right) catalysts.

\section{Results and discussion}

\section{Catalyst characterization}

In STEM analysis of the synthesized catalysts Ni particles smaller than $20 \mathrm{~nm}$ were detected in all samples, with a major fraction smaller than $10 \mathrm{~nm}$, again for all samples. The low loading of $\mathrm{Ni}$ and the low number of detected particles (14 for REF and $1 \mathrm{Na}$, around 30 for all other samples) did not allow for a proper statistical analysis, especially when the possible variation of the PSD on the $\mathrm{Ni} / \mathrm{ZrO}_{2}$ system is considered. For example, Charisiou et al. report a PSD from $20 \mathrm{~nm}$ to $80 \mathrm{~nm}$ for an $8 \mathrm{wt}$. $\% \mathrm{Ni} / \mathrm{ZrO}_{2}$ catalyst characterized via STEM-HAADF. ${ }^{42}$ Another primary characterization tool for the $\mathrm{Ni}-\mathrm{PSD}$ of $\mathrm{Ni} / \mathrm{ZrO}_{2}$ catalysts is $\mathrm{H}_{2}$ chemisorption. While this method allows estimating an averaged diameter, the exact $\mathrm{ZrO}_{2}$ morphology can also strongly impact the average $\mathrm{Ni}$ size. ${ }^{43}$ In contrast to frequent literature reports of successful $\mathrm{H}_{2}$ chemisorption, no $\mathrm{H}_{2}$ uptake at $30^{\circ} \mathrm{C}$ was observed. It is possible for metal particles to be partially covered by the support after prolonged reduction at high temperatures, which significantly reduces $\mathrm{H}_{2}$ uptake. ${ }^{44-}$ ${ }^{46}$ Steib et al. have observed $\mathrm{ZrO}_{\mathrm{x}}$ clusters on $\mathrm{Ni}$ particles in a $\mathrm{Ni}$ / $\mathrm{ZrO}_{2}$ system. ${ }^{47}$ Therefore, the chemisorption results can be seen as proof of a partial coverage of the Ni particles by the support. Temperature-programmed reduction (TPR) has been used in the past to compare the particle size of supported Ni catalysts. The TPR profiles for the current $\mathrm{Ni} / \mathrm{ZrO}_{2}$ catalysts are summarized in Fig. 2. Deconvolution of the TPR profiles leads to three peaks in all cases with the maxima at $350^{\circ} \mathrm{C}, 456^{\circ} \mathrm{C}$ and
$510{ }^{\circ} \mathrm{C}$ for pure $\mathrm{Ni} / \mathrm{ZrO}_{2}$. Assuming an experimental error of $20^{\circ} \mathrm{C}$, then one can consider the positions of peaks 1 and 3 to be unaffected by the promoter addition. Only the position of the intermediate peak 2 is shifted to lower temperatures for all promoted catalysts. $1 \mathrm{Mn}$ must be mentioned separately, since here the positions of peaks 2 and 3 shift more substantially than for the catalysts promoted with alkali me tals. A more interesting effect can be noted when analysing the relative peak area of the three reduction peaks. In short, all promoters increase the area of the highest temperature peak at the expense of the two others. Except for $1 \mathrm{Mn}$, this increase comes mainly at the cost of the lowest temperature peak. Increasing the loading of $\mathrm{Cs}$ or $\mathrm{K}$ once again increases the lowest temperature peak, as seen in Fig. 3

Previous studies indicate that in TPR analysis of supported $\mathrm{Ni}$ catalysts smaller $\mathrm{NiO}$ clusters are reduced at higher temperatures. In contrast, large $\mathrm{NiO}$ particles on the support can be considered bulk NiO. ${ }^{48-50}$ This rule cannot be applied universally, however. Available literature on Mn-promoted Co and $\mathrm{Ni}$ catalysts shows that shifts in reduction temperature are not necessarily caused by changes in Ni particle size but can also be affected by the formation of solid solutions during synthesis. ${ }^{51,52}$ The promoter itself can also decrease the reducibility of the Ni active phase. Mixed oxides of alkali metals and nickel have mainly been reported for $\mathrm{Ni}^{3+} .{ }^{53}$ However, we found no indication of $\mathrm{Ni}^{3+}$ in our samples and this is not expected after calcination at $700^{\circ} \mathrm{C}$. 


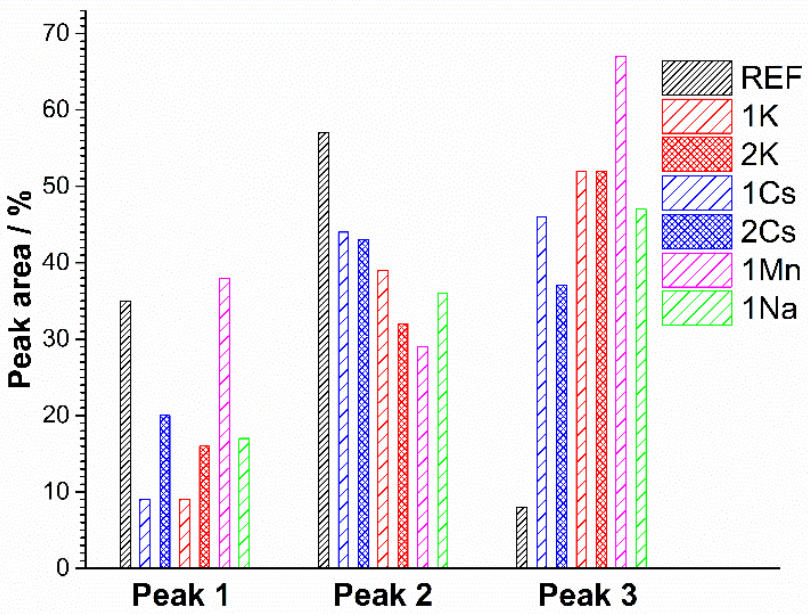

Fig. 3 Relative distribution of peak areas observed in TPR.

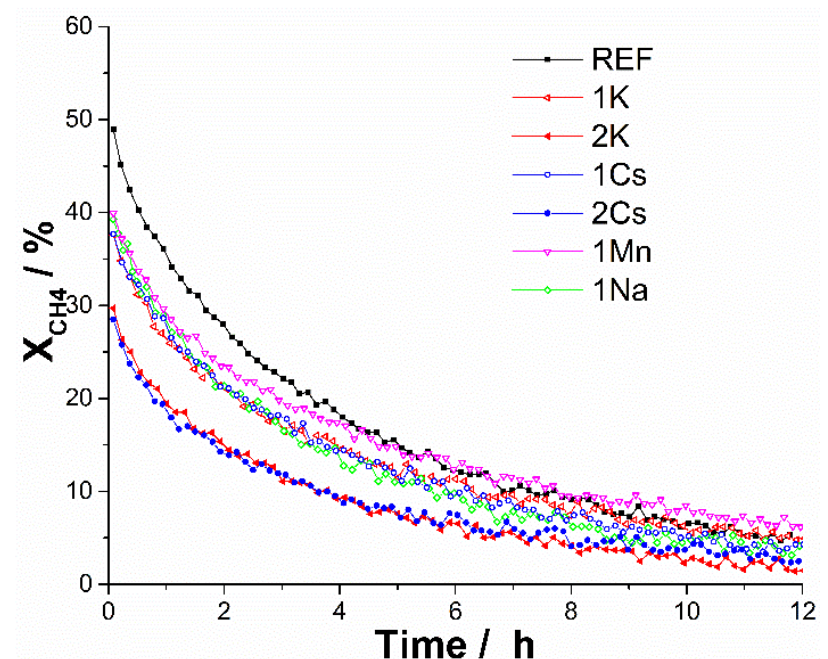

Fig. 4 Methane conversion over promoted and non-promoted $\mathrm{Ni} / \mathrm{ZrO}_{2}$ as a function of time-on-stream at $650{ }^{\circ} \mathrm{C}, 30 \mathrm{mg}$ sample, $80 \mathrm{~mL} \mathrm{~min}^{-1}\left(20 \% \mathrm{CH}_{4}, 20 \% \mathrm{CO} 2\right.$ in $\left.\mathrm{N}_{2}\right)$.

Instead, the TPR curves are in good agreement with the results of Peters et al. for pure $\mathrm{Ni} / \mathrm{ZrO}_{2} .{ }^{50}$ We propose that a correlation between reducibility and particle size is also appropriate for alkali-promoted $\mathrm{Ni} / \mathrm{ZrO}_{2}$. Thus, we attribute here peak 1 bulk to $\mathrm{NiO}$ and peaks 2 and 3 to dispersed $\mathrm{Ni}$ species with different degrees of interaction with the support. ${ }^{50}$

To summarize, our TPR data show, that the addition of alkali promoters reduces the amount of "bulk" nickel (peak 1). All alkali promoters increase the highest temperature peak also at the expense of the intermediate peak. However, an increase in alkali loading again increases the percentage of "bulk" nickel. It depends on the promoter in question, which of the two "dispersed nickel" peaks is affected by this readjustment. This concept of an optimal promoter loading for nickel distribution mirrors the TEM analyses of Park et al. ${ }^{54}$ When adding various alkali metals to $\mathrm{Ni} / \mathrm{SiO}_{2}$, they also noticed a smaller average $\mathrm{Ni}$ particle size for low promoter loadings and an growth in particle size with increased promoter loading.

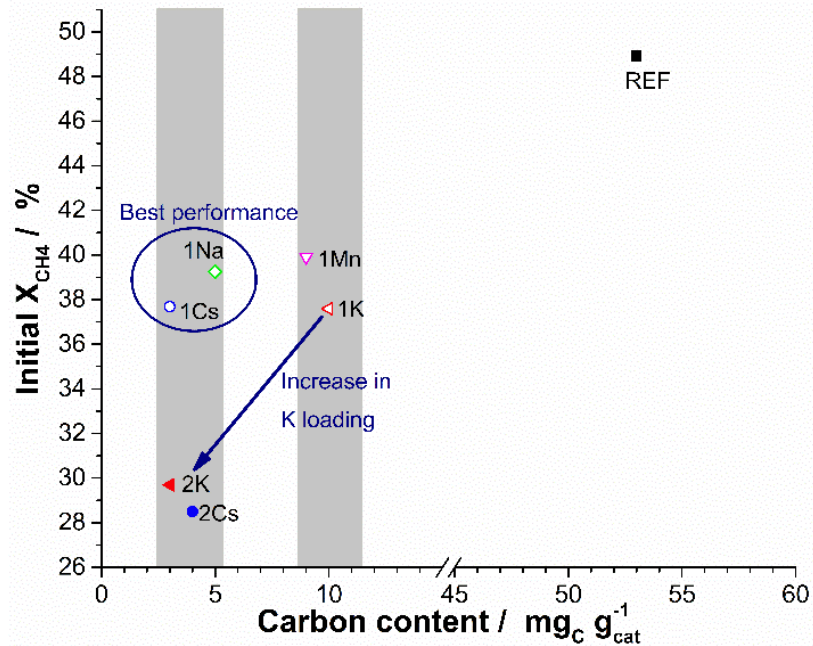

Fig. 5 Initial methane conversion of the samples plotted over the carbon content after 12 hours of coking.

\section{Catalytic activity}

The catalytic runs were carried out with very low loadings of the active metal under conditions at which coking is thermodynamically favourable. This allowed us to observe a significant deactivation for all catalysts during the $12 \mathrm{~h}$ activity test. The results of the catalytic runs are summarized in Fig. 4, in which the methane conversion is shown for all samples. For the $\mathrm{CO}_{2}$ conversion, we refer to the SI. For all catalysts, the increase in the promoter loading gave rise to a decreased conversion. Interestingly, at identical loadings, the catalysts with different promoters show similar levels of conversion (Fig. 4). These data suggest that regardless of the choice of promoter, a similar number of active sites in the catalyst was blocked by promoter addition.

Following this line of thought, samples with higher promoter loadings should be more resistant to coking and deactivate less. Yet, in all cases the conversion decreases considerably within $12 \mathrm{~h}$ TOS and after $6-8 \mathrm{~h}$ the measured values differ only marginally between the samples. Catalyst deactivation in dry reforming is frequently caused by coke formation, but sintering can also play a significant role. For example, the weak interactions between $\mathrm{ZrO}_{2}$ and $\mathrm{Ni}$ have been proposed to accelerate $\mathrm{Ni}$ sintering and thus catalyst deactivation during dry reforming. ${ }^{39}$ Pronounced sintering would thus be a credible explanation for the observed behaviour.

A strong impact of sintering may obscure differences between the different promoters. The different promoters do appear to block a similar amount of active sites. The question that remains is, if the effect on the catalyst stability is the same or if differences exist between the promoters. For example, one promoter may be more effective at blocking the most coke forming sites. To elucidate these potential differences, the coke contents on the spent catalysts was analysed and quantified.

\section{Coke characterization}

The carbon content of spent samples was analysed with TGAMS. The data are summarized in Fig. 5. In short, the nonpromoted REF contains $53 \mathrm{mgc}^{-1}$ cat and the coke loading of all 
promoted samples was substantially lower. In this group, samples $1 \mathrm{Mn}$ and $1 \mathrm{~K}$ contain the most coke with 9 and $10 \mathrm{mg}_{\mathrm{c}} \mathrm{g}^{-1}$ cat respectively. Using caesium and sodium as promoters reduces the coke content by around $50 \%$ to 3 or $5 \mathrm{mgc}^{-1}$ cat. Increasing the loading of potassium reduces the coke content further ( $3 \mathrm{mgc}_{\mathrm{c}} \mathrm{g}_{\text {cat }}$ for $2 \mathrm{~K}$ ). $2 \mathrm{Cs}$ is on a similar level with $4 \mathrm{mgc}^{-1}$ cat. As mentioned previously, the increased promoter loadings of $2 \mathrm{Cs}$ and $2 \mathrm{~K}$ also reduce the initial methane conversion substantially.

Published literature shows that increasing the loading of alkali metal promoter reduces both the conversion and the amounts of coke deposits. ${ }^{18}$ For the K- promoted samples, this correlation holds. Increasing the $\mathrm{K} / \mathrm{Ni}$ ratio from $1 / 10(1 \mathrm{~K})$ to $2 / 10(2 \mathrm{~K})$ further reduces the coke, albeit only by small overall amounts when comparing the drop in coke content from REF to $1 \mathrm{~K}$. This is in line with the previously proposed concept of site blocking by the promoters, which implies that the most active coke forming sites are quickly blocked by the promoter. ${ }^{23,25}$ The remaining coke is not formed on step-edge sites but on $\mathrm{Ni}$ ensembles of a minimal size. ${ }^{21,55}$ Larger quantities of the promoter are then necessary to cover all such ensembles sufficiently to prevent further coke formation. For Cs the situation is slightly different as a $\mathrm{Cs} / \mathrm{Ni}$ ratio of $1 / 10$ (1Cs) is already enough to reduce the carbon content to $3 \mathrm{mgc}_{\mathrm{c}} \mathrm{g}_{\text {cat. In }}$ our work we were not able to obtain a catalyst that coked less.

To summarize, in our work caesium and sodium were most effective at reducing the overall coke content than manganese and potassium at low promoter loadings. At higher promoter loadings, the low total coke content prevents any differentiation between the samples.

Literature has already hinted at Cs being more effective at reducing the carbon formation than K. ${ }^{20}$ Horiuchi et al. compared the relative effectiveness of sodium and potassium in suppressing coke formation. Still, their data do not establish a clear trend. ${ }^{26}$ Alkali metals are well-known coke gasification catalysts (e.g. ${ }^{56,57}$ ) and typically outperform manganese oxides in this respect. ${ }^{58,59}$ Thus, the comparable coke content of $1 \mathrm{Mn}$ and $1 \mathrm{~K}$ implies the site-blocking mechanism dominating in these cases. The superior performance of $1 \mathrm{Cs}$ and $1 \mathrm{Na}$ may well be due to an increased gasification activity.

A different effectivity at reducing the coke content may well result in different coke structures for the individual promoters. A TEM analysis reveals two visually distinctive types of carbon: carbon fibres and "bulk" coke deposits. Examples for both structures are given in Fig. 6 (and Figs. S1 - S3). Additional carbon species and changes within the structures of these two carbon types cannot be ruled out. However, the main contributions to the overall coke composition are to be expected of these two carbon types due to their visually noticeable presence.

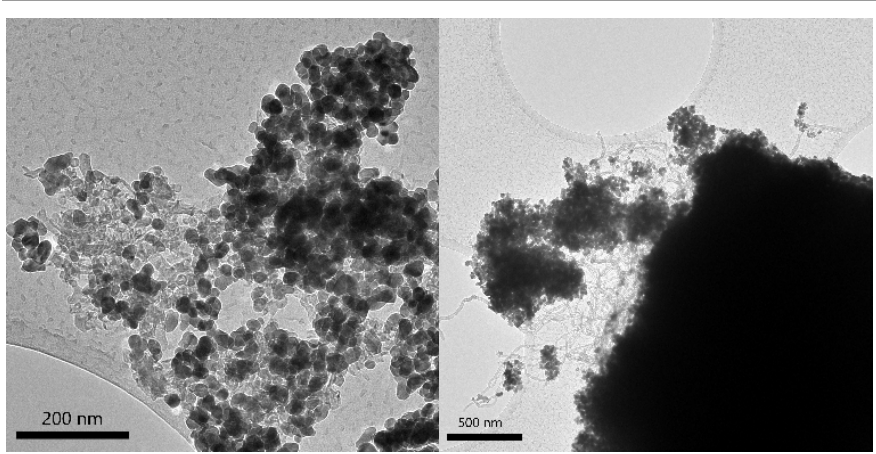

Fig. 1 TEM images of "bulk" carbon (left - sample REF) and carbon filaments (right sample $1 \mathrm{Mn}$ ) after $12 \mathrm{~h}$ coking treatment.

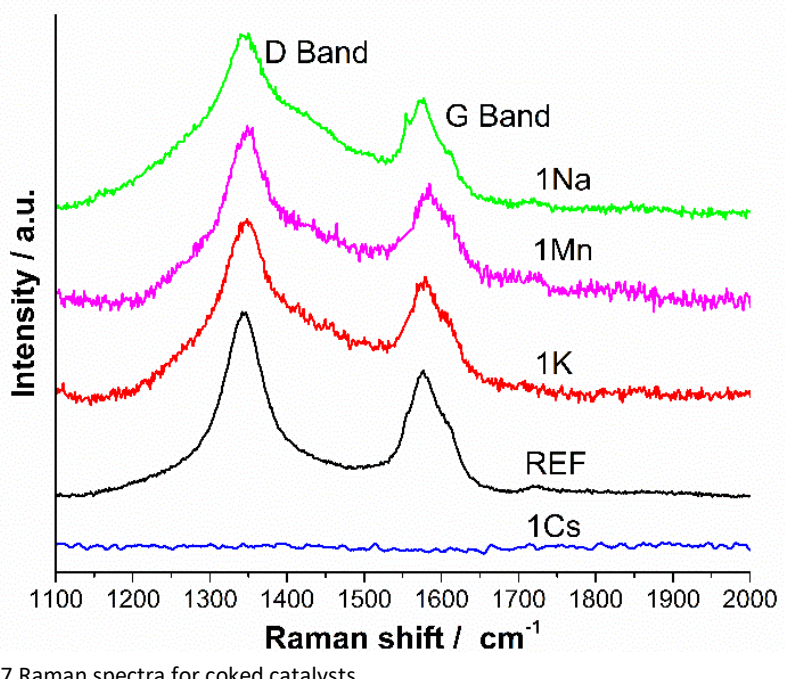

Raman spectroscopy is a potential tool to probe the nature of the carbon species in dry reforming catalysts. ${ }^{60}$ In particular the graphitic coke species are probed, since Raman spectra of carbons are typically dominated by the characteristic bands of $\mathrm{sp}^{2}$ species. ${ }^{61} \mathrm{Fig} .7$ shows the spectra for the pure $\mathrm{Ni} / \mathrm{ZrO}_{2}$ and all samples with a $1 / 10$ promoter ratio. The only exception is 1Cs for which no Raman spectrum of the carbon could be obtained.

$\mathrm{Sp}^{2}$ carbons typically display two different Raman bands: The D band (approx. $1360 \mathrm{~cm}^{-1}$ ) and $\mathrm{G}$ band (approx. $1560 \mathrm{~cm}^{-1}$ ). The latter has been correlated to the tangential vibrations of $\mathrm{C}$ $C$ bonds, while the D-band indicates the defect density within the graphitic structure. ${ }^{60}$ In Fig. 7 all samples exhibit these two bands. To further differentiate between the samples, the relative intensity of the $D$ - and G-bands can be calculated for the different samples. A high value of the $\mathrm{I}_{\mathrm{D}} / \mathrm{I}_{\mathrm{G}}$ is a sign of a carbon with high defect density. Carbon nanotubes are highly structured graphitic species and should thus lead to a more pronounced G-band relative to the D-band. ${ }^{62}$

The $I_{D} / I_{G}$ values for all samples are in the range of $1.45-1.55$, whereas Stroud et al. reported values between 0.8 and 2.0.60 However, they also reported different ratios for measurements carried out on different regions of the same catalyst. These observations can be explained by considering the contribution 
of carbon fibres with their low defect density. During the TEM analysis described above a distinct clustering of carbon fibres was observed. Stroud et al. did not report coke quantification but the catalysts investigated contained roughly 5 times more $\mathrm{Ni}$ than the samples in this work and were tested for longer periods of time. ${ }^{60}$ This ought to lead to a significantly higher coke contents and thus more clusters of carbon fibres. It is possible that the different ratios of $\mathrm{I}_{\mathrm{D}} / \mathrm{I}_{\mathrm{G}}$ reported previously were caused by analysing areas of coke containing vastly different percentages of carbon fibres. Less clusters of fibres make their contribution to the measured Raman spectra unlikely in this work. Indeed, the results in Fig. 7 fit better to a "softer", more defect-rich carbon, i.e. bulk carbon. This implies that the crystallinity of the bulk carbon is not significantly affected by the choice of promoter.

In addition, the pure $\mathrm{Ni} / \mathrm{ZrO}_{2}$ and all samples with a promoter/ $\mathrm{Ni}$ ratio of $1 / 10$ were analysed with ${ }^{13} \mathrm{C}-\mathrm{NMR}$ to investigate the character of the carbon species further. The presence of magnetic nickel on the catalysts required high spinning frequencies and short relaxation times to obtain information on the carbon without interference. At the same time, the low carbon content required measurement periods of approx. $24 \mathrm{~h}$ per sample. The spectra for the samples $1 \mathrm{~K}$ and $1 \mathrm{Na}$ are very similar to the sample $1 \mathrm{Cs}$, respectively (see Fig. S9). Therefore, in Fig. 8, only the spectra REF, $1 \mathrm{Mn}$ and $1 \mathrm{Cs}$ are shown.

All samples clearly show a peak in the range of 0-50 ppm, typically associated with alkanes and $\mathrm{sp}^{3}$-hybridized carbons. The presence of $\mathrm{sp}^{3}$-hybdridized carbon could be explained by the formation of amorphous carbon, which contains both $\mathrm{sp}^{2}$ and $\mathrm{sp}^{3}$-hybdridized carbons (e.g. ${ }^{63,64}$ ). Pure amorphous carbon would then consist of two peaks around $30 \mathrm{ppm}$ and $120 \mathrm{ppm}$. Instead, REF and $1 \mathrm{Mn}$ contain a significant peak around $100 \mathrm{ppm}$. For $1 \mathrm{~K}$ the main peak decreases slowly with increasing chemical shift and a smaller peak is visible at approx. $120 \mathrm{ppm}$. For $1 \mathrm{Cs}$ and $1 \mathrm{Na}$, instead of a distinct peak at $120 \mathrm{ppm}$, a shoulder can still be identified in this range. Additionally, these two samples also display a comparatively sharp peak at $167 \mathrm{ppm}$.

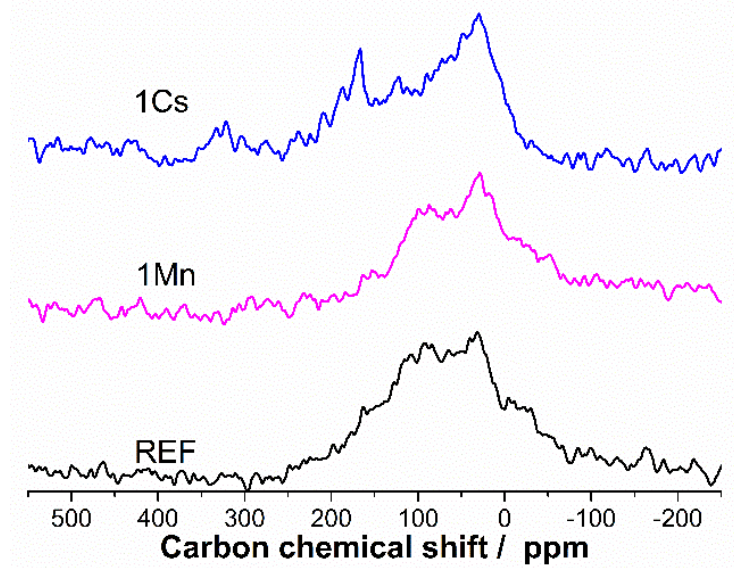

Fig. $8{ }^{13} \mathrm{C}-\mathrm{NMR}$ spectra of the non-promoted (REF), Mn-promoted (1Mn) and $\mathrm{Cs}$ promoted (1Cs) Ni/ $\mathrm{ZrO}_{2}$
The contribution between $50-100 \mathrm{ppm}$ may be due to several reasons. Firstly, hydrogen-poor amorphous carbon has been observed to display clear peaks or shoulders in the $\mathrm{sp}^{3}$ peak at around 70 ppm. ${ }^{64}$ The less hydrogen is present in the amorphous carbon, the clearer this peak at $70 \mathrm{ppm}$ becomes. Secondly, the existence of carbon fibres was proven by TEM for almost all samples. These fibres are typically compared to carbon nanotubes. Pristine nanotubes display a chemical shift of $100-130$ ppm, depending on their diameter (e.g. ${ }^{65}$ ). At the same time, the encapsulation of hydrocarbons within carbon nanotubes typically reduces the chemical shift of these molecules in ${ }^{13} \mathrm{C}$-NMR. ${ }^{65}, 66 \mathrm{Sp}^{2}$-hydrocarbons (typically: 120 $160 \mathrm{ppm}$ ) encapsulated in the fibres could then contribute in the range of $80-100 \mathrm{ppm}$.

Thus, we consider the carbon deposits to contain amorphous carbon with a noticeable $\mathrm{sp}^{3}$-contribution. For REF and $1 \mathrm{Mn}$ the NMR spectra further show the presence of significant amounts of carbon fibres. For the alkali- promoted samples, the small peak or shoulder at $120 \mathrm{ppm}$ is more in keeping with a small $\mathrm{sp}^{2}$-contribution in amorphous carbon. The comparison of the different spectra shows that while all promoters reduce overall carbon levels, alkali metals are more effective at preventing the formation of carbon fibres. This is in line with TEM analysis, where carbon fibres were easier to detect for REF and $1 \mathrm{Mn}$ than for the alkali-promoted samples.

The NMR results for all alkali-promoted samples are mostly comparable, especially since at such low coke contents contaminations could quickly influence the signal (Fig. S9). The only exception is the peak mentioned above at approx. $167 \mathrm{ppm}$ for $1 \mathrm{Cs}$ and $1 \mathrm{Na}$, which is absent for $1 \mathrm{~K}$. The peak is attributed to carbonate species present in the spent catalyst in the form of either alkali carbonate formation or as $\mathrm{Zr}\left(\mathrm{CO}_{3}\right)_{2}$. A clear identification was not possible, since the chemical shift of the different carbonates differ only slightly. ${ }^{67-70}$ However, the coke contents of all three samples are in the same order of magnitude. If the peak were due to $\mathrm{Zr}\left(\mathrm{CO}_{2}\right)_{3}$ it should also be visible in the spectrum of $1 \mathrm{~K}$. This is a strong indication of the presence of $\mathrm{Na}_{2} \mathrm{CO}_{3}$ and $\mathrm{Cs}_{2} \mathrm{CO}_{3}$.

The detection of carbonates is in line with the previous proposal of enhanced coke gasification for the samples 1Cs and $1 \mathrm{Na}$. Carbonate formation is commonly considered an important step in the (earth) alkali-catalysed gasification of carbon with $\mathrm{CO}_{2} .{ }^{37,71,72}$ The accepted order of catalytic activity in coal gasification of the alkali metals used in this work is $\mathrm{Cs}>\mathrm{K}>\mathrm{Na} .{ }^{72}$ However, this relative activity is affected by the dispersion of the alkali metals on the carbon, since $\mathrm{Na}$ is known to agglomerate on carbon surfaces. ${ }^{37}$ At the same time, the $\mathrm{CO}_{2}$ absorption capacity of $\mathrm{Na}_{2} \mathrm{ZrO}_{3}$ has been reported previously. ${ }^{73}$, ${ }^{74}$ For $\mathrm{Na}$-promoted $\mathrm{Ni} / \mathrm{ZrO}_{2}$ a coke gasification cycle including $\mathrm{Na}_{2} \mathrm{ZrO}_{3}$ and $\mathrm{Na}_{2} \mathrm{CO}_{3}$ has already been proposed for dry reforming of methane. ${ }^{27}$ Thus, whereas $\mathrm{Cs}$ itself is a very active gasification catalyst, the activity of $\mathrm{Na}$ may be increased through interaction with the support.

Summarizing, the coke quantification shows that all promoters reduce the coke content significantly compared to the non-promoted $\mathrm{REF} \mathrm{Ni} / \mathrm{ZrO}_{2}$ catalyst. However, $1 \mathrm{Na}$ and $1 \mathrm{Cs}$ only contain approx. $50 \%$ of the carbon deposited on $1 \mathrm{Mn}$ and 
1K. Raman spectroscopy did not reveal any differences the $\mathrm{sp}^{2}$-contribution of the bulk carbon. At the same time TEM and ${ }^{13} \mathrm{C}-\mathrm{NMR}$ show a higher propensity of $1 \mathrm{Mn}$ and REF to form carbon fibres. The overall composition of the coke deposits appears to be a function of the promoter, but the structure of the individual carbon species is not. Additionally, NMR showed significant contributions of $\mathrm{sp}^{3}$-hybridized carbon in all samples, which is assumed to be amorphous carbon of the "soft" bulk carbon. Operation at temperatures such as $650^{\circ} \mathrm{C}$ and higher is expected to produce coke with high levels of graphitization. ${ }^{13,75}$ This is such an accepted assumption that in reviews on methane reforming, the words graphite and coke have been used interchangeably. ${ }^{12}$ The presence of $\mathrm{sp}^{3}$ signals shows, that, at least at $650^{\circ} \mathrm{C}$, full graphitization cannot yet be assumed.

Furthermore, the NMR spectra of $1 \mathrm{Na}$ and $1 \mathrm{Cs}$ show the presence of carbonates indicating the presence of $\mathrm{Cs}_{2} \mathrm{CO}_{3}$ and $\mathrm{Na}_{2} \mathrm{CO}_{3}$ and thus carbon gasification activity for the two samples with the lowest coke content. The results in this publication show that the same promoted catalyst can achieve site blocking and carbon gasification. However, the overall catalytic effectiveness is not directly correlated to the results of classical coal gasification. It appears that the superior interaction of $\mathrm{Na}$ and $\mathrm{ZrO}_{2}$ compared to $\mathrm{Na}$ and coal cause $1 \mathrm{Na}$ to outperform $1 \mathrm{~K}$, despite $\mathrm{K}$ being reported to be the superior coal gasification catalyst.

\section{Conclusion}

A series of $\mathrm{Ni} / \mathrm{ZrO}_{2}$ with different promoter metals and promoter ratios was synthesized. TPR studies led to the observation of different effects of the metal promotors on $\mathrm{Ni}$ reducibility, which indicate smaller $\mathrm{Ni}$ particles when adding small promoter amounts. STEM analysis reveals that for all samples the majority of the Ni particles is smaller than $10 \mathrm{~nm}$ before the reaction. Despite varying effects on the reducibility of $\mathrm{Ni}$, the different promoters lead to almost identical conversion in the dry reforming of methane at $650{ }^{\circ} \mathrm{C}$. A difference only becomes noticeable in the analysis of coked samples.

While all promoters strongly reduce the coke content compared to the pristine $\mathrm{Ni} / \mathrm{ZrO}_{2}$, the degree of coke reduction depends on the promoter. ${ }^{13} \mathrm{C}-\mathrm{NMR}$ analysis shows the presence of $\mathrm{sp}^{3}$-hybridized carbon in all samples, despite literature frequently assuming full graphitization at these temperatures. In combination with TEM analysis it could be established that alkali metals are more effective at suppressing fibre growth than manganese. At the same time, samples promoted with sodium or caesium coked less than a sample coked with potassium. These two samples are also the only ones, for which carbonate species could be detected in NMR. Therefore, it is proposed that the lower coke content is caused by coke gasification. Comparison with literature indicates that the higher than expected activity of the Na-promoted sample can be attributed to superior interactions between $\mathrm{Na}$ and the $\mathrm{ZrO}_{2}$ support compared to $\mathrm{Na}$ on carbon in typical coal gasification.

\section{Conflicts of interest}

There are no conflicts to declare.

\section{Acknowledgements}

Financial support by the CatC1Chem project of NWO, BASF, SABIC and Sasol is gratefully acknowledged.

\section{Notes and references}

1 BP Energy Outlook 2019 edition, https://www.bp.com/content/dam/bp/businesssites/en/global/corporate/pdfs/energy-economics/energyoutlook/bp-energy-outlook-2019.pdf, (accessed Apr. 17, 2020).

2 T. L. Roussière, PhD, Karlsruhe Institute of Technology, 2013.

3 I. K. van Ravenhorst, C. Vogt, H. Oosterbeek, K. W. Bossers, J. G. Moya-Cancino, A. P. van Bavel, A. M. J. van der Eerden, D. Vine, F. M. F. de Groot, F. Meirer and B. M. Weckhuysen, Angew. Chem. Int. Ed., 2018, 57, 11957-11962.

4 R. Gaikwad, A. Bansode and A. Urakawa, J. Catal., 2016, 343, 127-132.

5 L. Tillmann, J. Schulwitz, A. van Veen and M. Muhler, Catal. Lett., 2018, 148, 2256-2262.

6 L. C. S. Kahle, T. Roussière, L. Maier, K. Herrera Delgado, G. Wasserschaff, S. A. Schunk and O. Deutschmann, Ind. Eng. Chem. Res., 2013, 52, 11920-11930.

7 J. A. Moulijn, A. E. van Diepen and F. Kapteijn, Appl. Catal. A. Gen., 2001, 212, 3-16.

8 N. A. K. Aramouni, J. G. Touma, B. A. Tarboush, J. Zeaiter and M. N. Ahmad, Renew. Sust. Energ. Rev., 2018, 82, 2570-2585.

9 H. Düdder, K. Kähler, B. Krause, K. Mette, S. Kühl, M. Behrens, V. Scherer and M. Muhler, Catal. Sci. Technol., 2014, 4, 33173328.

10 B. AlSabban, L. Falivene, S. M. Kozlov, A. Aguilar-Tapia, S. Ould-Chikh, J.-L. Hazemann, L. Cavallo, J.-M. Basset and K. Takanabe, Appl. Catal. B. Environ., 2017, 213, 177-189.

11 S. A. Theofanidis, V. V. Galvita, H. Poelman and G. B. Marin, ACS Catal., 2015, 5, 3028-3039.

12 J. R. Rostrup-Nielsen, J. Sehested and J. K. Nørskov, in Advances in Catalysis, Academic Press, 2002, vol. 47, pp. 65139.

13 C. H. Bartholomew, Appl. Catal. A. Gen., 2001, 212, 17-60.

14 R. T. K. Baker, P. S. Harris, J. Henderson and R. B. Thomas, Carbon, 1975, 13, 17-22.

15 J. Zhang, H. Wang and A. K. Dalai, J. Catal., 2007, 249, 300-310.

16 I. Chen and F. L. Chen, Ind. Eng. Chem. Res., 1990, 29, 534-539.

17 F. Frusteri, F. Arena, G. Calogero, T. Torre and A. Parmaliana, Catalysis Communications, 2001, 2, 49-56.

18 J. Juan-Juan, M. C. Román-Martínez and M. J. Illán-Gómez, Appl. Catal. A. Gen., 2006, 301, 9-15.

19 T. Osaki and T. Mori, J. Catal., 2001, 204, 89-97.

20 C. Ping, H. Zhao-Yin and Z. Xiao-Ming, Chin. J. Chem., 2005, 23 847-851.

21 J. R. Rostrup-Nielsen, J. Catal., 1984, 85, 31-43.

22 S. Arora and R. Prasad, RSC Advances, 2016, 6, 108668108688.

23 H. S. Bengaard, I. Alstrup, I. Chorkendorff, S. Ullmann, J. R. Rostrup-Nielsen and J. K. Nørskov, J. Catal., 1999, 187, 238244.

24 F. Besenbacher, I. Chorkendorff, B. S. Clausen, B. Hammer, A. M. Molenbroek, J. K. Nørskov and I. Stensgaard, Science, 1998, 279, 1913-1915. 
25 H. S. Bengaard, J. K. Nørskov, J. Sehested, B. S. Clausen, L. P. Nielsen, A. M. Molenbroek and J. R. Rostrup-Nielsen, J. Catal. 2002, 209, 365-384.

26 T. Horiuchi, K. Sakuma, T. Fukui, Y. Kubo, T. Osaki and T. Mori, Appl. Catal. A. Gen., 1996, 144, 111-120.

27 M. Németh, D. Srankó, J. Károlyi, F. Somodi, Z. Schay, G. Sáfrán, I. Sajó and A. Horváth, Catal. Sci. Technol., 2017, 7, 5386-5401.

28 Z. Hou, O. Yokota, T. Tanaka and T. Yashima, Appl. Surf. Sci., 2004, 233, 58-68.

29 S.-H. Seok, S. H. Han and J. S. Lee, Appl. Catal. A. Gen., 2001, 215, 31-38.

30 D. W. Flaherty, W.-Y. Yu, Z. D. Pozun, G. Henkelman and C. B. Mullins, J. Catal., 2011, 282, 278-288.

31 A. Díaz, D. R. Acosta, J. A. Odriozola and M. Montes, J. Phys. Chem. B, 1997, 101, 1782-1790.

32 W. D. Mross, Catal. Rev., 1983, 25, 591-637.

33 A. Parmaliana, F. Arena, F. Frusteri, N. Mondello and N. Giordano, in Stud. Surf. Sci. Catal., eds. C. H. Bartholomew and J. B. Butt, Elsevier, 1991, vol. 68, pp. 489-492.

34 A. Ehrmaier, L. Löbbert, M. Sanchez-Sanchez, R. BermejoDeval and J. Lercher, ChemCatChem, 2020, DOI: 10.1002/cctc.202000349

35 Littlewood, X. Xie, M. Bernicke, A. Thomas and R. Schomäcker Catal. Today, 2015, 242, 111-118.

36 J. A. Moulijn and F. Kapteijn, in Carbon and Coal Gasification: Science and Technology, eds. J. L. Figueiredo and J. A. Moulijn Springer Netherlands, Dordrecht, 1986, DOI: 10.1007/978-94009-4382-7 6, pp. 181-195.

37 J. A. Moulijn and F. Kapteijn, Carbon, 1995, 33, 1155-1165.

38 J. L. Rogers, M. C. Mangarella, A. D. D’Amico, J. R. Gallagher, M. R. Dutzer, E. Stavitski, J. T. Miller and C. Sievers, ACS Catal., 2016, 6, 5873-5886.

39 R.-j. Zhang, G.-f. Xia, M.-f. Li, Y. Wu, H. Nie and D.-d. Li, J. Fuel Chem. Techn., 2015, 43, 1359-1365.

40 C. Nederlof, V. Zarubina, I. Melián-Cabrera, H. J. Heeres, F. Kapteijn and M. Makkee, Catal. Sci. Technol., 2013, 3, 519526

41 R. J. Berger, J. Pérez-Ramírez, F. Kapteijn and J. A. Moulijn, Chem. Eng. Sci., 2002, 57, 4921-4932.

42 N. D. Charisiou, S. L. Douvartzides, G. I. Siakavelas, L. Tzounis, V. Sebastian, V. Stolojan, S. J. Hinder, M. A. Baker, K. Polychronopoulou and M. A. Goula, Catalysts, 2019, 9, 676.

43 R. K. Singha, A. Shukla, A. Yadav, S. Adak, Z. Iqbal, N. Siddiqui and R. Bal, Applied Energy, 2016, 178, 110-125.

44 E. Taglauer, in Handbook of Heterogeneous Catalysis, eds. G. Ertl, H. Knözinger, F. Schüth and J. Weitkamp, 2008, DOI 10.1002/9783527610044.hetcat0051, pp. 1014-1029.

45 G. Marcelin and J. E. Lester, J. Catal., 1985, 93, 270-278.

46 D. M. Stockwell, A. Bertucco, G. W. Coulston and C. O. Bennett, J. Catal., 1988, 113, 317-324.

47 M. Steib, Y. Lou, A. Jentys and J. A. Lercher, ChemCatChem, 2017, 9, 3809-3813.

48 C. Li and Y.-W. Chen, Thermochimica Acta, 1995, 256, 457 465.

49 B. Mile, D. Stirling, M. A. Zammitt, A. Lovell and M. Webb, J. Molec. Catal., 1990, 62, 179-198.

50 A. Peters, F. Nouroozi, D. Richter, M. Lutecki and R. Gläser, ChemCatChem, 2011, 3, 598-606.

51 F. Morales, D. Grandjean, A. Mens, F. M. F. de Groot and B. M. Weckhuysen, J. Phys. Chem. B, 2006, 110, 8626-8639.

52 W. L. Vrijburg, E. Moioli, W. Chen, M. Zhang, B. J. P. Terlingen, B. Zijlstra, I. A. W. Filot, A. Züttel, E. A. Pidko and E. J. M. Hensen, ACS Catal., 2019, 9, 7823-7839.

53 L. D. Dyer, B. S. Borie and G. P. Smith, J. Am. Chem. Soc., 1954, 76, 1499-1503.

54 C. Park and M. A. Keane, J. Colloid Interface Sci,, 2002, 250, 37-48.
55 N. T. Andersen, F. Topsøe, I. Alstrup and J. R. Rostrup-Nielsen, J. Catal., 1987, 104, 454-465.

56 F. Kapteijn, O. Peer and J. A. Moulijn, Fuel, 1986, 65, 13711376

57 D. W. McKee, Fuel, 1983, 62, 170-175

58 M. Arjmand, H. Leion, T. Mattisson and A. Lyngfelt, Appl. Energy, 2014, 113, 1883-1894.

59 M. Keller, H. Leion and T. Mattisson, Energy Technol., 2013, 1 273-282.

60 T. Stroud, T. J. Smith, E. Le Saché, J. L. Santos, M. A. Centeno, H. Arellano-Garcia, J. A. Odriozola and T. R. Reina, Appl. Catal. B. Environ., 2018, 224, 125-135.

61 A. C. Ferrari, Solid State Commun., 2007, 143, 47-57.

62 M. S. Dresselhaus, G. Dresselhaus, A. Jorio, A. G. Souza Filho and R. Saito, Carbon, 2002, 40, 2043-2061.

63 R. H. Jarman, G. J. Ray, R. W. Standley and G. W. Zajac, Appl. Phys. Lett., 1986, 49, 1065-1067.

64 J. Braddock-Wilking, S. H. Lin and B. J. Feldman, Solid State Commun., 2001, 119, 19-21.

65 E. Abou-Hamad, M. R. Babaa, M. Bouhrara, Y. Kim, Y. Saih, S Dennler, F. Mauri, J. M. Basset, C. Goze-Bac and T. Wågberg, Phys. Rev. B, 2011, 84, 165417.

66 N. A. Besley and A. Noble, J. Chem. Phys., 2008, 128, 101102.

67 F. Takasaki, K. Fujiwara, Y. Nakajima, T. Nishikawa, H. Masu, M. Imanari, Y. Hidaka and N. Ogawa, Dalton Trans., 2015, 44, 645-652.

68 R. E. Cowley, N. J. DeYonker, N. A. Eckert, T. R. Cundari, S. DeBeer, E. Bill, X. Ottenwaelder, C. Flaschenriem and P. L. Holland, Inorg. Chem., 2010, 49, 6172-6187.

69 N. A. Eckert, S. Vaddadi, S. Stoian, R. J. Lachicotte, T. R. Cundari and P. L. Holland, Angew. Chem. Int. Ed., 2006, 45, 6868-6871.

70 R. E. Cowley, N. A. Eckert, S. Vaddadi, T. M. Figg, T. R. Cundari and P. L. Holland, J. Am. Chem. Soc., 2011, 133, 9796-9811.

71 D. Cazorla-Amorós, A. Linares-Solano, F. H. M. Dekker and F. Kapteijn, Carbon, 1995, 33, 1147-1154.

72 S. G. Chen and R. T. Yang, Energy \& Fuels, 1997, 11, 421-427.

73 H. G. Jo, H. J. Yoon, C. H. Lee and K. B. Lee, Ind. Eng. Chem Res., 2016, 55, 3833-3839.

74 G. G. Santillán-Reyes and H. Pfeiffer, Intl. J. Greenhouse Gas Control, 2011, 5, 1624-1629.

75 J. M. Ginsburg, J. Piña, T. El Solh and H. I. de Lasa, Ind. Eng. Chem. Res., 2005, 44, 4846-4854. 


\section{Table of Contents Graphic}
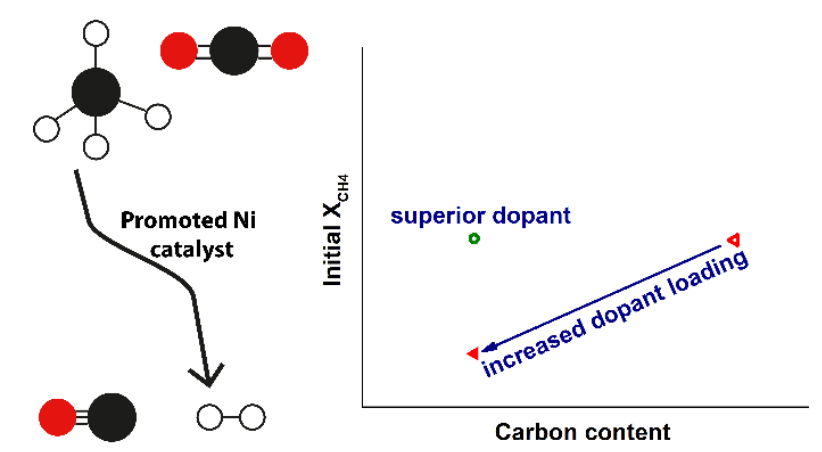


\section{Supplementary information - Impact of small promoter amounts on coke structure in dry reforming over $\mathrm{Ni} / \mathrm{ZrO}_{2}$}

Robert Franz ${ }^{\mathrm{a}, \mathrm{b}}$, Tobias Kühlewind ${ }^{\mathrm{b}}$, Genrikh Shterk ${ }^{\mathrm{c}}$, Edy Abou-Hamad ${ }^{\mathrm{d}}$, Alexander Parastaev ${ }^{\mathrm{e}}$, Evgeny Uslamin ${ }^{a}$, Emiel Hensen ${ }^{\mathrm{e}}$, Freek Kapteijn ${ }^{\mathrm{b}}$, Jorge Gascon ${ }^{\mathrm{c}}$, Evgeny Pidko*a

${ }^{a}$ Inorganic Systems Engineering Group, Department of Chemical Engineering, Delft University of Technology, Van der Maasweg 9, 2629 Hz Delft, The Netherlands

Email: e.a.pidko@tudelft.nl

${ }^{b}$ Catalysis Engineering, Department of Chemical Engineering, Delft University of Technology, Van der Maasweg 9, 2629 HZ Delft, The Netherlands

${ }^{c}$ Advanced Catalytic Materials, KAUST Catalysis Center, King Abdullah University of Science and Technology, Thuwal 23955, Saudi Arabia

${ }^{d}$ Core Labs, King Abdullah University of Science and Technology, Thuwal 23955, Saudi Arabia ${ }^{\mathrm{e}}$ Inorganic Materials \& Catalysis group, Eindhoven University of Technology, PO Box 513, 5600 MB Eindhoven, The Netherlands

\section{Content}

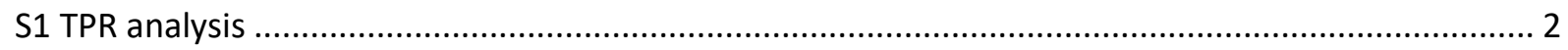

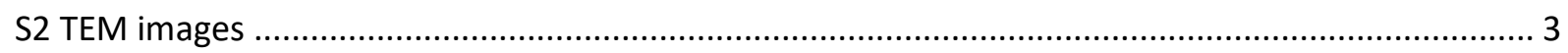

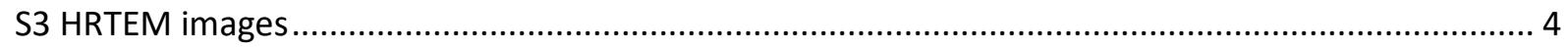

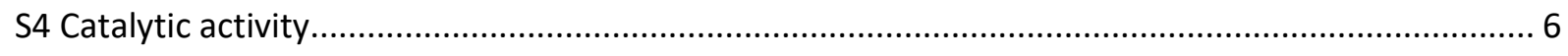

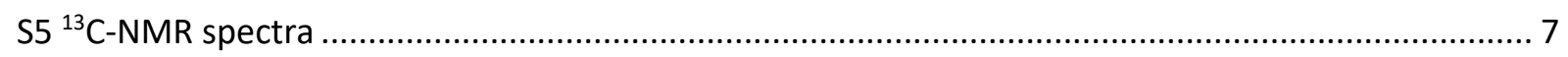


S1 TPR analysis

Table S1: Reduction peaks observed during TPR profile deconvolution.

\begin{tabular}{c|c|c|c} 
Sample & Peak 1 $\left[{ }^{\circ} \mathrm{C}\right]$ & Peak 2 $\left[{ }^{\circ} \mathrm{C}\right]$ & Peak 3 $\left[{ }^{\circ} \mathrm{C}\right]$ \\
\hline REF & $350^{\circ} \mathrm{C}$ & $460^{\circ} \mathrm{C}$ & $510{ }^{\circ} \mathrm{C}$ \\
$1 \mathrm{~K}$ & $350^{\circ} \mathrm{C}$ & $420^{\circ} \mathrm{C}$ & $520^{\circ} \mathrm{C}$ \\
$2 \mathrm{~K}$ & $340{ }^{\circ} \mathrm{C}$ & $400{ }^{\circ} \mathrm{C}$ & $490{ }^{\circ} \mathrm{C}$ \\
$1 \mathrm{Na}$ & $320^{\circ} \mathrm{C}$ & $390{ }^{\circ} \mathrm{C}$ & $490{ }^{\circ} \mathrm{C}$ \\
$1 \mathrm{Cs}$ & $340^{\circ} \mathrm{C}$ & $410^{\circ} \mathrm{C}$ & $510^{\circ} \mathrm{C}$ \\
$2 \mathrm{Cs}$ & $370^{\circ} \mathrm{C}$ & $440{ }^{\circ} \mathrm{C}$ & $530{ }^{\circ} \mathrm{C}$ \\
$1 \mathrm{Mn}$ & $330^{\circ} \mathrm{C}$ & $380^{\circ} \mathrm{C}$ & $470{ }^{\circ} \mathrm{C}$
\end{tabular}




\section{S2 TEM images}
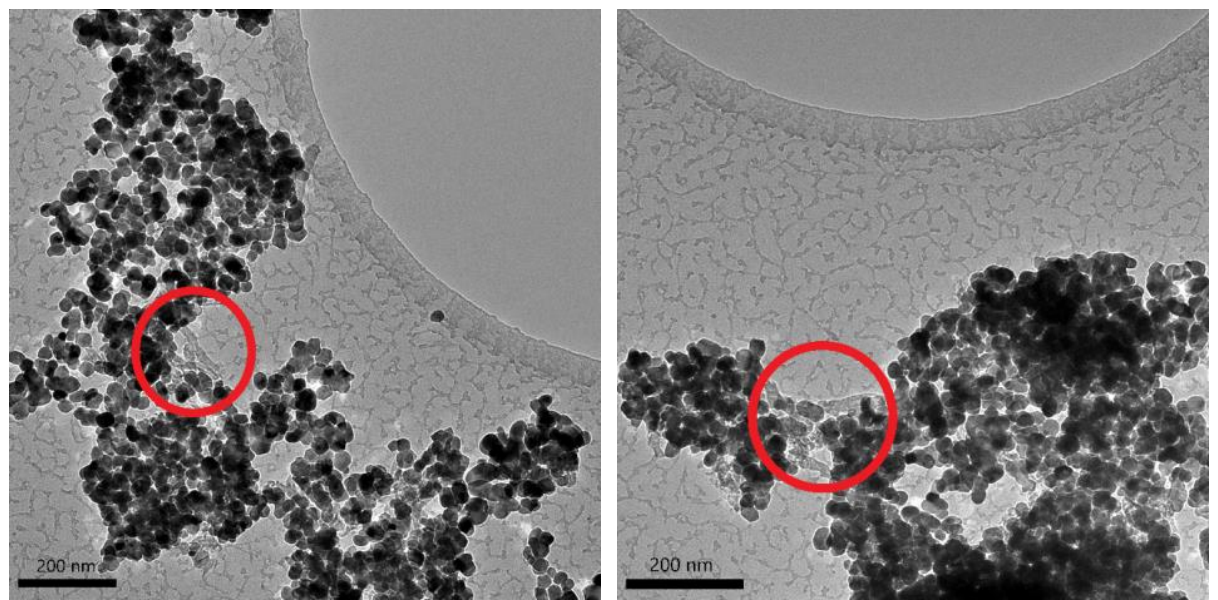

Fig. S1: Coke structures visible on sample $1 \mathrm{~K}$ ) after $12 \mathrm{~h}$ coking treatment.
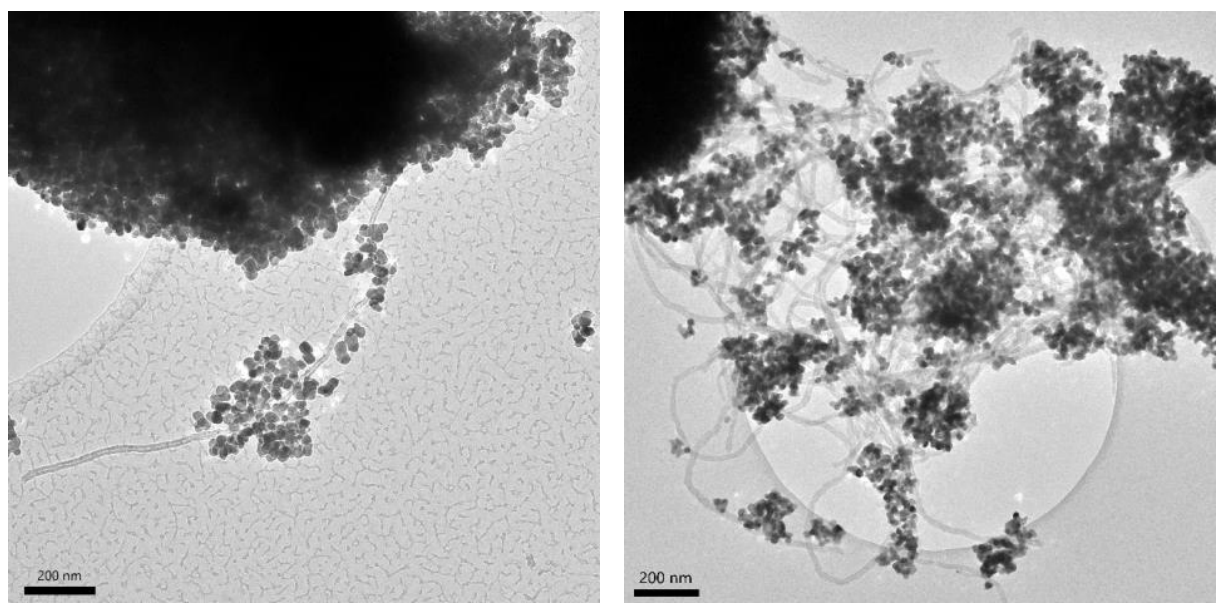

Fig. S2: Coke structures visible on sample $1 \mathrm{Na}$ (left) and REF (right) ) after $12 \mathrm{~h}$ coking treatment.

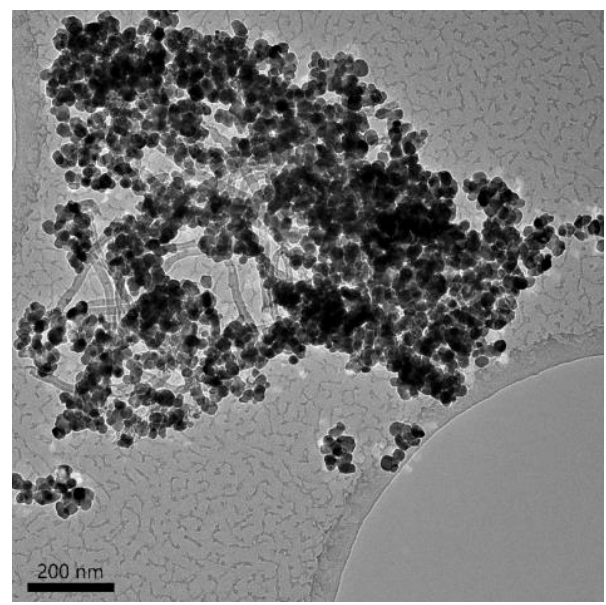

Fig. S3: Coke structure visible on sample $1 \mathrm{Mn}$ ) after $12 \mathrm{~h}$ coking treatment. 
S3 HRTEM images

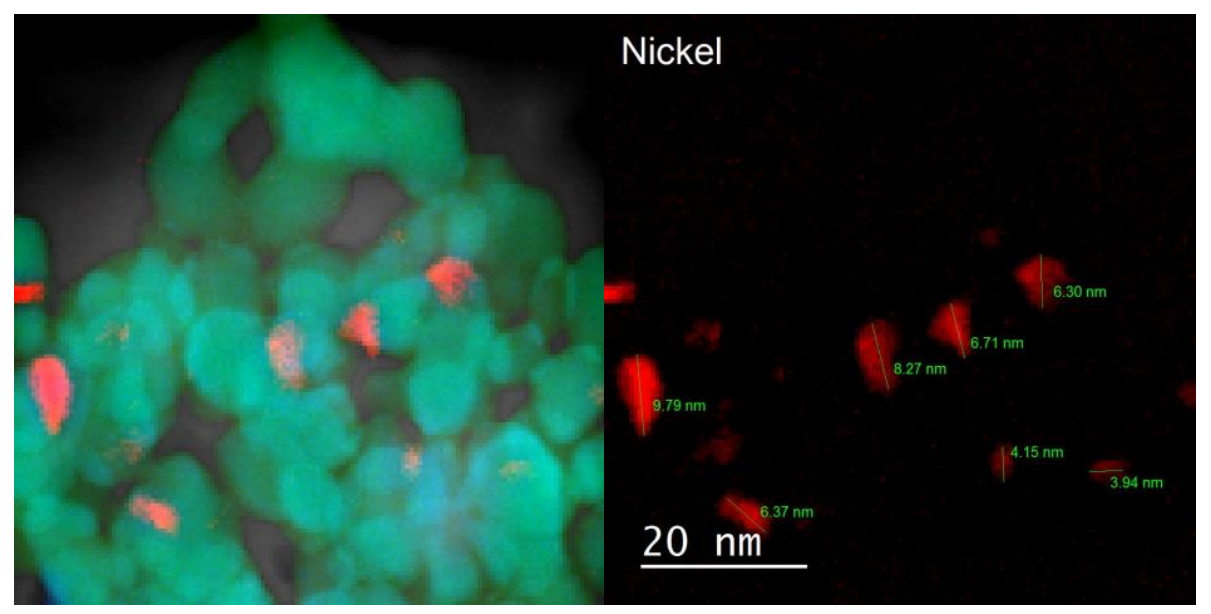

Fig. S4: Example of Ni particles visible on sample 2Cs.

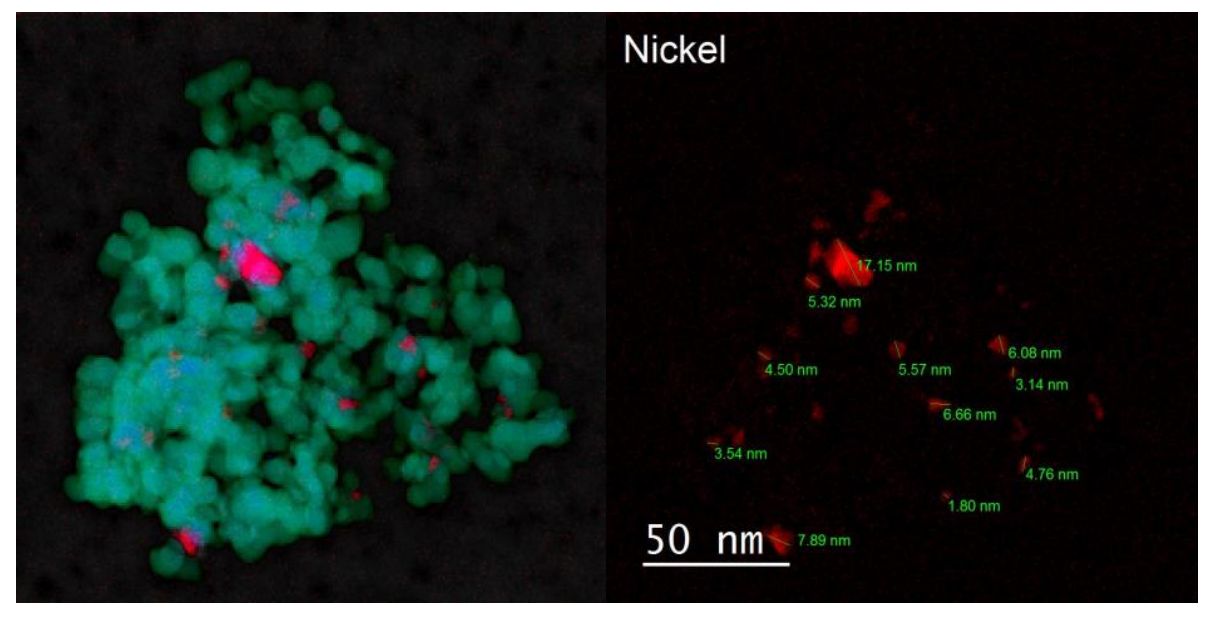

Fig. S5: Example of Ni particles visible on $1 \mathrm{~K}$.

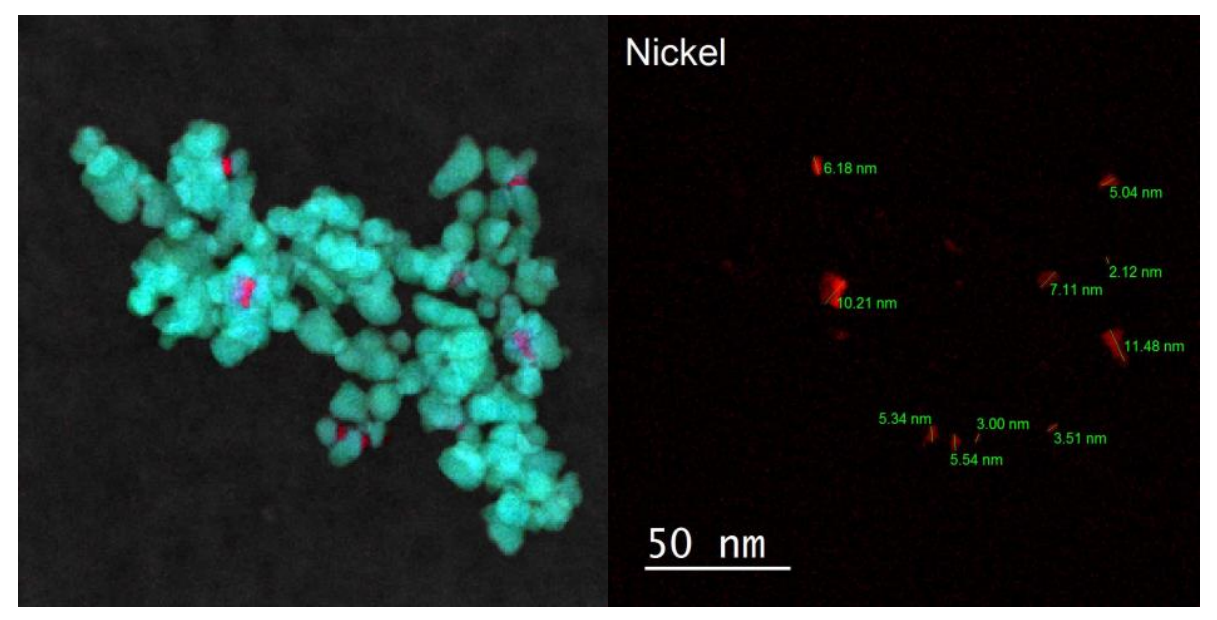

Fig. S6: Example of $\mathrm{Ni}$ particles visible on $1 \mathrm{Mn}$. 


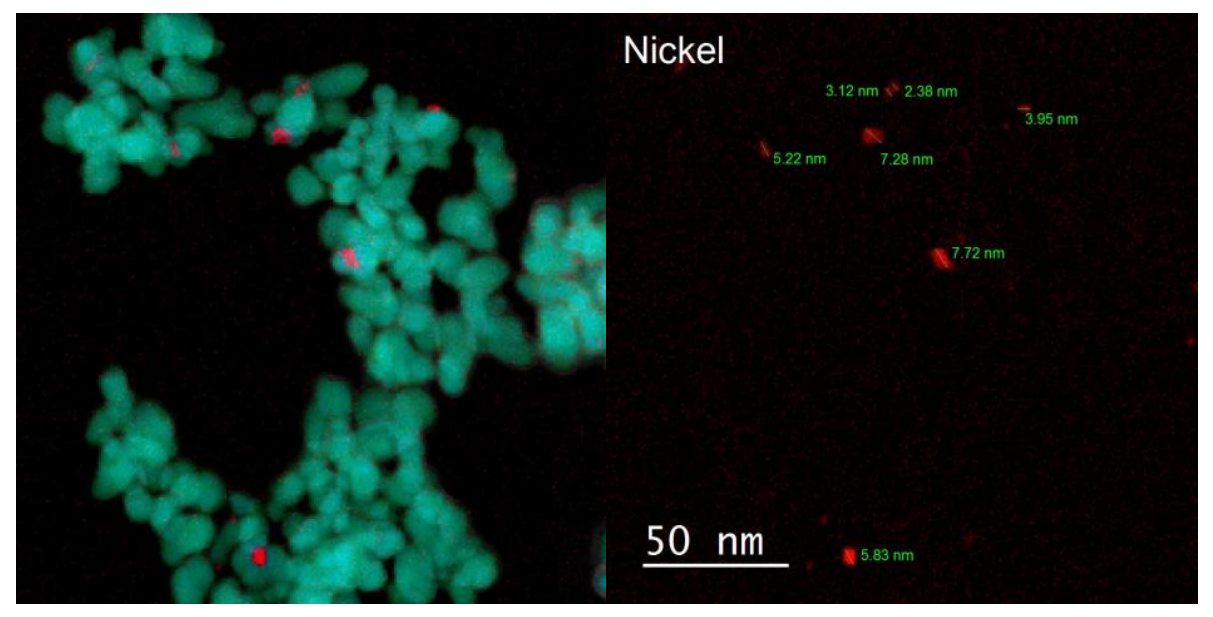

Fig. S7: Example of Ni particles visible on REF. 
S4 Catalytic activity

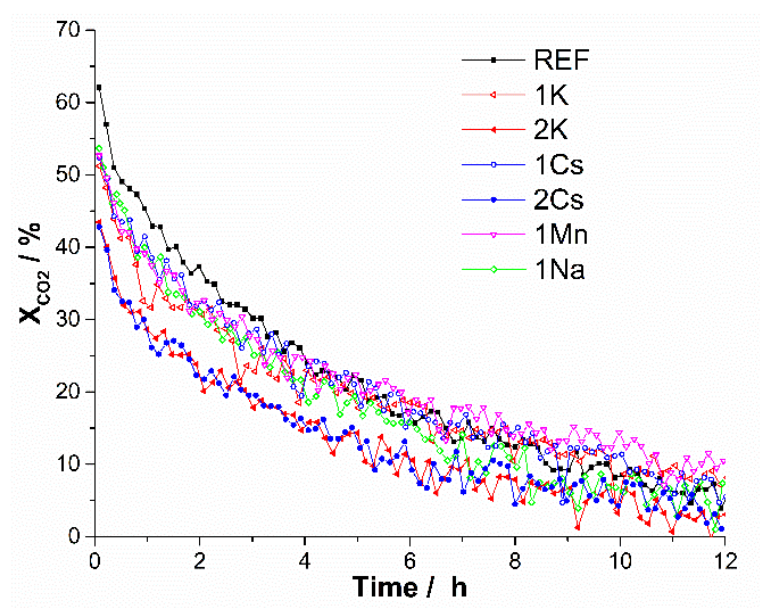

Fig. S8: $\mathrm{CO}_{2}$ conversion over promoted and non-promoted $\mathrm{Ni} / \mathrm{ZrO}_{2}$ as a function of time-on-stream; $650{ }^{\circ} \mathrm{C}, 1$ bar, $30 \mathrm{mg}$ catalyst, $80 \mathrm{~mL} \mathrm{~min}{ }^{-1}\left(20 \% \mathrm{CH}_{4}, 20 \% \mathrm{CO}_{2}\right.$ in $\left.\mathrm{N}_{2}\right)$. 
S5 ${ }^{13}$ C-NMR spectra

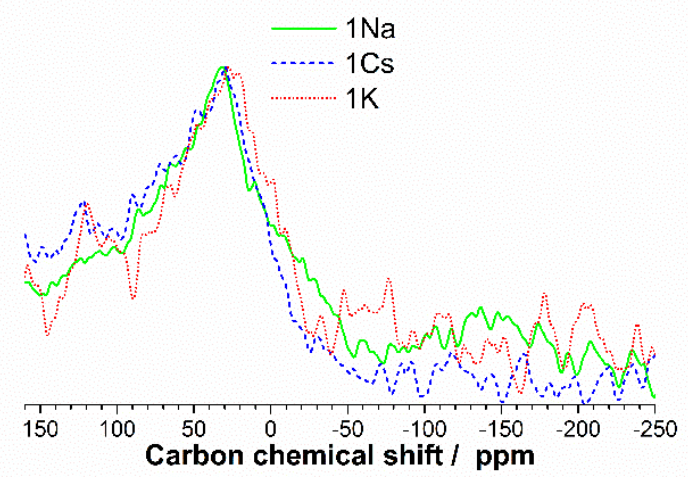

Fig S9: ${ }^{13} \mathrm{C}-\mathrm{NMR}$ spectra of the alkali-promoted $\mathrm{Ni} / \mathrm{ZrO}_{2}$ catalysts with a ratio of promoter/ $\mathrm{Ni}$ ratio of $1 / 10$. 